\title{
URBAN EXPANSION - URBAN SHRINKING CONSIDERATIONS ON BRASOV AGGLOMERATION URBAN DYNAMICS
}

\author{
Cătălin Sârbu
}

University of Architecture and Urban Planning „Ion Mincu”, Bucharest, Romania

\begin{abstract}
The study of the vision of spatial development at different scales can often suggest different solutions, due to the different priorities imposed by the distinct territorial governance levels. In this respect, it can be useful to point out the meanings of the terms like urban growth, urbanisation, urban expansion or urban sprawl and their relevance for the future of a defined human settlements system. The presentation of the case of Brasov city and its agglomeration emphasised some of the problems of urban dynamic.
\end{abstract}

Key words: Urban growth, Urban expansion, Urban shrinking.

Article Info: Manuscript Received: February 28, 2012; Revised: May 5, 2012; Accepted: May 15, 2012; Online: May 29,2012

\section{Introduction}

The urban and territorial planning offers visions of development that sometimes evolve at the convergence with the political decidents priority whom results are relevant for the planners activity. When analytical and prospective studies must approach different spatial levels and somehow different administrative priority, one of the problems of the professionals is to conciliate different visions of the development with the findings of the research.

The case of spatial development of Brasov city in Romania within the territory of urban agglomeration rise an interesting question: what kind of spatial expansion can be sustainable in the condition of a severe shrinking of the population and taking into consideration the difference on spatial development visions of two governance levels?

The objective of this article is to explain the main development perspective of two different planning studies, starting from the geographical situation of the Brasov Depression („Barsa Country”) and going to the spatial development proposals for the level of Brasov city and Brasov Urban Agglomeration.

\footnotetext{
* Correspondence address:

Address: "Ion Mincu" University of Architecture and Urbanism, str. Academiei 18-20, sector 1, o10014, Bucharest, Romania.

Telephone: +4.021.3077.180

Email: sarbu52@yahoo.com
}

\section{Methodology}

The problem of the interrelations of the city with its surrounding territories is not a new one, but when there are different approaches for the two different scales from the administrative, legal and political points of view, there are challenges on how to deal with the impacts of different development approaches.

The two studies on Brasov territory ${ }^{1}$ made at different spatial scales offered distinct hierarchical levels of analysis and different data, leading to the conclusions and helping to propose specific territorial objectives for development. The plans made for distinct spatial levels and oriented to specific local authorities with different competence for decision, having possible divergence of the visions upon spatial development, are the basis for the considerations and conclusions.

The analysis has been made for the main demographic and economic indicators as well as for social and public network, for the two spatial levels accordingly. The different purposes of the distinct type of documentation, one of them mainly a strategic spatial development document for a great area, the other one more oriented to the operational sectors (mainly to building norms as support for immediate investments), have not become convergent on their effects due to the different

${ }^{1}$ Sârbu, 2007 and Sârbu, 2001 
visions of the communities, despite being established as complementary spatial plans in Romanian specific legislation. These lead us for an attempt to understand the contradictions of the spatial development at two different scales.

To understand these approaches, some terminology specifications appear to be useful.

\section{Terminology issues}

Generally speaking, urbanisation means the continuous process of multiplication of the cities and towns all over the world but as well of the urban way of life, values and culture and not for the least of the urbanity meaning specific mentalities and behaviour ${ }^{2}$. Usually, urbanisation is understood as an expansion (the growth), of the towns and cities areas.

Urban expansion implies demographic growth and/or spatial expansion of dense built areas, this covering a part of what it's usually understood by urbanisation, or in a more administrative approach, extension of the built-up areas ${ }^{3}$. These different concepts, referring to distinct (but sometime overlapping) aspects of the urban dynamics, imply not only quantitative approaches but as well qualitative understanding.

Another concept very often used to describe the process of the outgrowth of the cities is urban sprawl $^{4}$. This is more addressing to the great cities and their surroundings, evolving to urban agglomerations, meanwhile surprising two apparent contradictory processes: expansion of the surfaces of built-up areas versus the diminishing of the population density and often the shrinking of the total population.

At regional scale, urban growth phenomena means the issue and development of urban agglomerations, spatial concentration of the population and economic activities, together with their functional restructuring, and not for the last, their growth and diversification. New dynamics lead to new institutional structures, in order to manage the complexity of the urban phenomena.

At the superregional and continental spatial scale, the urban expansion could be understood as the appearing of the new great urban agglomerations and metropolitan areas.

\footnotetext{
2 "Urban development is the process of emergence of the world dominated by cities and by urban values" (Clark 1982, quoted. in Basudeb B, 2010, p. 2).

${ }^{3}$ Areas where there is allowed to build, according to the local urban planning norms.

4 "Urban sprawl is the less compact outgrowth of a core urban area exceeding the population growth rate and having a refusal character or impact on sustainability of environment and human" (Basudeb B 2010, p.9)
}

All these approaches underline the urban dynamics as permanent processes all along the human history as an expression of the continuous aims of the civilisations to access the resources of the territory. In this view, the human settlements network can be seen as one of the main and complex functional structure to access these resources 5 .

\section{Expansion, but not only growth}

"Urban growth, urban expansion and urban sprawl are sometimes used synonymously by the common people, although they are different. Urban growth is a sum of increase in developed land. One of its forms is expansion" (Basudeb B, 2010, p.10).

Some phenomena associated with urban expansion can also be seen as their reasons to appear: population growth, independence of decision, physical geography, demand of more living space, transportation, country-living desire and many others (Giovanni M, 2008 p.18).

Mobility, in all its understandings is one of the most important of these: it can mean the physical activities oriented to the accessibility of the different zones of the territory (on all multiscalar spatial approaches), but also the spatial mobility of the activities, including also the residential mobility of the population.

This process leads also to the dynamics of the intensity of land use (including the problems of the built-up areas density).

And not for the last, expansion is accompanied by the changing of the land use, the recycling of the land plots and re-using of the buildings.

\section{Expansion versus shrinking}

It is a common place to say that the limits of the growing are usually depending on the limits of the resources (spatial, natural, technological, financial, socio-demographic and professional), also understood as systemic limits, for more and more wider territorial integrated spaces, going to the global.

In this approach, the contraction can be considered exclusively as results of the relationship with the external environment of a certain territory? Having in mind the complexity of the territorial system, urban expansion and shrinking can be understood if we consider different levels (and

\footnotetext{
${ }^{5}$ The increasing of quantity of anthropic energy is possible by developing the complexity of the resources absorption channels. Human settlements network represents by its structure and functions one of the major channels for an intense and continuous access to the complex resources of the Natural Capital. (Sârbu, 2006, p. 9)
} 
sectors), of the territorial processes. If we refer to endogenous causes, it cannot be taking into consideration only structural and demographic evolution. It also has to consider the exogenous causes of the general stream of the urban dynamics (the access to resources, macroeconomic phenomena $^{6}$, and geopolitical reasons ${ }^{7}$, all of these meaning the mega tendency of the globalization).

\section{The complexity of the urban dynamics and polycentric development approach}

The urban dynamics has different expressions at different spatial scales and different sectorial levels. As a general observation we can also identify different dynamics of the components defining the expansion: the higher resilience of the physical compounds versus higher changing rates regarding socioeconomic and economic elements of the territorial system.

It is important that despite the usual approach focused on the morphology of the spatial evolution of a human settlement system, all the terms are linked to the process of urban change, this implying not only the spatial structures but as well the changing of the activities (land uses), new fluxes generated and institutional matters ${ }^{8}$. Some of these possible changes are today more and more identified with polycentric pattern of spatial dynamic ${ }^{9}$ The different spatial scale approach offer different visions on the polycentric development as a possible structuring drive force for the urban settlement and for the territorial system scales ${ }^{10}$.

By consequence, the complexity of the urban dynamics phenomena appears in the wide range of expressions of the morphological evolutions, illustrated in a series of different terms and concepts

\footnotetext{
${ }^{6}$ Brasov illustrates the effects of the strong interventions of the centralized economic decisions before the'gos, its disruptions of development being explained by the changing balance of potential of development and the capacity for revaluation, as explained on "Individual urban dynamic model" (Ioan I, 2004, page12-14)

7 "Privatization in Central and Eastern European Member States has led to private housing estate companies building massively in peri-urban areas with few constraints on architectural quality, land use or possible master plans. These different factors may explain why urban sprawl is in progress around both growing and shrinking cities" Bauer, A, Röhl, D, Haase, D \& Schwarz, N, 2011 (EC 2011, p. 26).

8 "Many of the definitions found in the literature tend to emphasize the idea of urban sprawl being a type of urban form or a pattern of urbanization, rather than a process of urban change". (Couch $C$, 2007, p.5).

9 "In most European countries strong polycentric urban systems (...) are developing networks, pooling resources and sharing functions with other cities" ". (Couch C, 2007, p.40).

10 "These poles have a different worth and different capacity for structuring urban space; however, they are not set out in an easily identifiable hierarchy..." (Giovanni M, 2008, p. 72)
}

(urban growth, urban expansion, urban sprawl, urban fringe a.o.) and as well in the appearance of new institutional structures and functions and their relationship.

\section{Results and interpretations}

Spatial potentials of Brasov agglomeration Brasov illustrated these complex and apparently contradictory evolutions, in fact faces of the urban dynamics.

The first observation refers to the central position of Brasov within the national territory (meaning a theoretical good accessibility from all directions if we don't consider the natural physical morphology of the national territory), that suggest to be relevant for its potential of development. This national potential for accessibility was historically developed by the old connexion ways at macro territorial scale, nowadays attempting to be reinforced by the new motorways Bucharest-Brasov-Oradea and motorways to Timisoara. Meanwhile, Brasov is one of the most important railroad national nodes.

Also, on the European scale, Brasov agglomeration is a Functional Urban Area (FUA), (Espon, 1.1.1./2004)

Another observation show that Brasov belong to an important urbanisation axe developing from South to the Nord (Russe-Giurgiu-Bucharest-PloiestiPrahova Valley-Brasov), with about 3 million people on a distance of $240 \mathrm{Km}$. This position can ensure (again theoretical), good opportunities for development by complementarity of territorial functions.

\section{The coherence of Brasov human settlements system and population shrinking}

At the scale of „Bârsa country”, and due to the geographical morphology, Brasov agglomeration appears to be one of the most coherent urban settlements systems in Romania, concentrating around 400 thousands inhabitants on a territory with a potential accessibility of less than 25 minutes by roads from the core of the agglomeration. This concentration show a density of population in the area (about 340 inh./sq.Km. over 3.5 time greatest than the national average of the density (around 80 inh./sq.Km.).

These theoretical geographic potentials for a coordinated development and by consequence for an urban expansion is also underlined by the diversity of touristic resources. The concentration of the human 


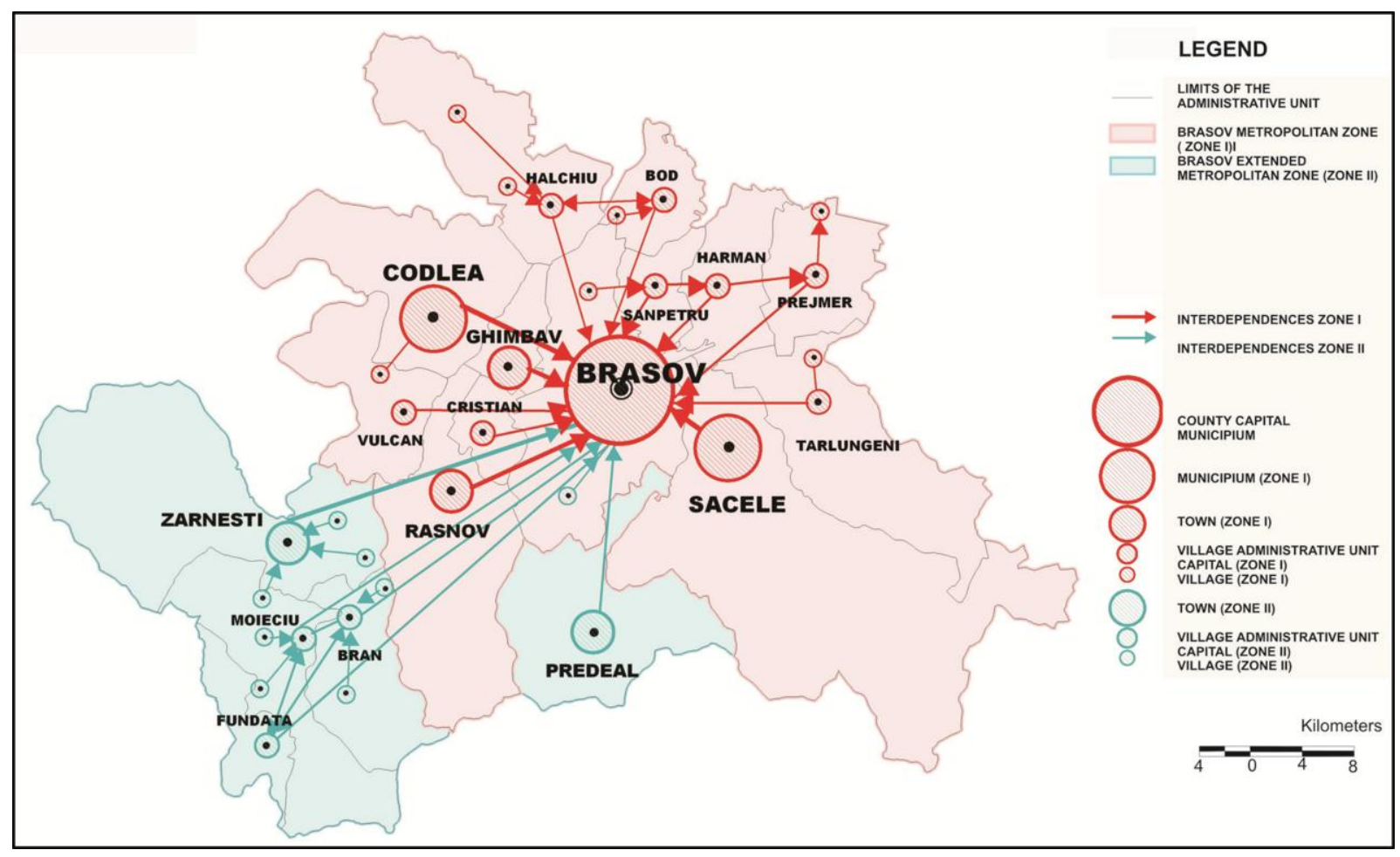

Figure 1. Human settlements system of Brasov agglomeration. Authors: C. Sârbu, I. Lupoaie

settlements in Brasov area provides a better potential to produce synergies and represents a $\mathrm{PUSH}^{11}$.

Despite these facts, the de-industrialisation process $^{12}$ leads to the shrinking of the population of the agglomeration, that decreased from 433 ooo inhabitants (in 1998), to 402 ooo (in 2006) and now under 390 ooo. Even in this situation, Brasov agglomeration remains one of the greatest in Romania (after Bucharest and Brăila-Galaţi urban system and close to other growth poles: Timişoara, Iaşi, Cluj and 10\% under Constanta ${ }^{13}$ ).

\footnotetext{
" "Morphological proximity is of course no guarantee of cooperation, but proximity does nevertheless provide cities with a better opportunity for functional integration. Our hypothesis is that cities with overlapping travel-to-work-areas have the best potential for developing synergies... This approximation also makes it possible to use population data at the NUTS 5 level, i.e. for municipalities. The resulting areas are labeled Potential Urban Strategic Horizons (PUSH)" (Espon 1.1.1./2004, p.13-14)

${ }^{12}$ Brasov city and its agglomeration already supports a disruption sock concerning its economic development after ' 9 os, after the quick industrialization development under the Communist regime, and is now suffering the impacts of globalization. Peter Hall and Kathy Pain pointed out that the capitals are "profoundly affected by the globalization of the economy and the progressive shift of advanced economies to information handling, whereby the great majority of the workforce no longer deals with material outputs" (Hall, P \& Pain, K 2006, page 25). This seems to be the case of Brasov city that is forced to find out the development of services, out of these, the tourism services ones.

${ }^{13}$ Taking into account the Romanian case, and the definition of the specified metropolitan areas (acc. to the 351 Romanian Law from din 2001 July $6^{\text {th }}$ ), the comparison considers the institutional legal structure (i.e. metropolitan associations of the municipalities and communities), based on specific urban studies. We underline the strong structural different human settlement structure (with more
}

Anyhow, the major natural and anthropic resources, in combination with relative orographic enclavization represent a physical potential for concentration of the activities and population, suggesting also a demographic expansion. The contradiction with the demographic reality means that the geographical advances for development and for an urban type of spatial expansion do not automatically leads to growth, due to the main driving force - general economic context.

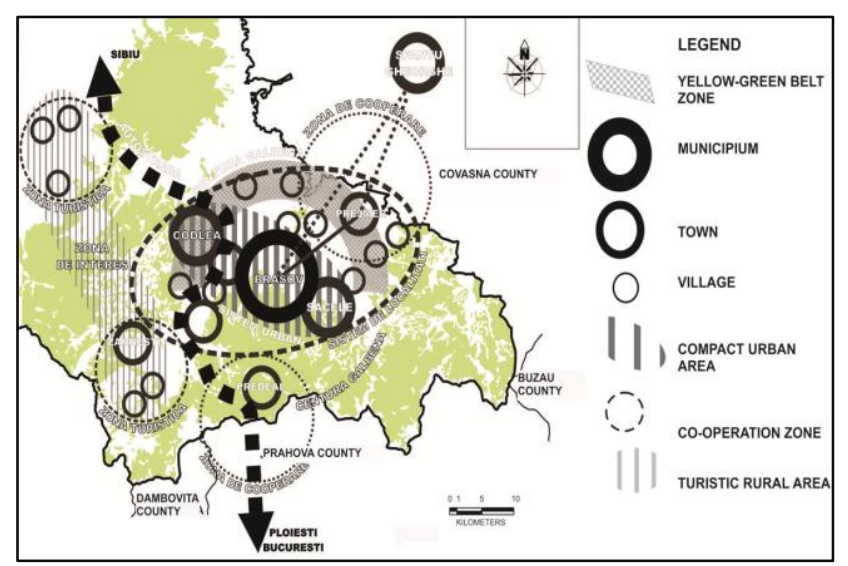

Figure 2. Possible spatial developing of Brasov agglomeration. Authors: C. Sârbu, L. Veluda

More, the proximity for important natural valuable areas and also of historical monuments, combined with the industrial decline, made that the

municipalities and towns) of Brasov and Constanta face to the other Romanian Growth Poles. (Author's note) 
land outside Brasov municipality have a higher price than some inside the city ${ }^{14}$.

The proposals for the near future can only address to a moderate way of urban spatial expansion. Taking into consideration the relative proximity of Brasov agglomeration to Sfântu-Gheorghe city (the neighbourhood county capital), a solution to reinforce this urban system is to concentrate a part of the development resources for a new urban settlements rising from rural (Prejmer), addressing to the quality of the features defining the urban quality of the life. The proposed green-yellow belt has the role to temperate the processes of agglutination of the Brasov city built-up areas with the surrounding communities.

Despite these consideration, the city decidents press for a spatial expansion of the built-up areas of Brasov. The possible advantage followed are decreasing the general built density for new residential areas, but also ensuring room for new economic capacity, when the economic context will allow for this, within the administrative boundaries of the city. Starting from these goals to create spatial conditions for expansion, Brasov city is supposed to be an area with potential for immigration.

In this respect, Brasov can be considered as a city with growth (for the built-up areas), but within the whole agglomeration territory, the spatial dynamics of the built-up areas represents an urban sprawl phenomena, finally leading to spatial agglutination. This management problem appears to belong to all the communities, requiring common solution to this common problem, due to the relative high geographical concentration of the human settlements in the area.

The municipality of Brasov want to attract as much as possible potential investors on its territory. Also, there is a run of the population from the collective block of flats to individual housing properties, resulting the necessity to have enough room for the development of new individual houses areas. By consequence, there is a continuous expansion of the built-up area and the necessity to ensure new urban poles for current social activities ${ }^{15}$. Around these poles is supposed to develop new physical urban structures.

\section{Conclusions}

Brasov agglomeration must be seen, beyond the „natural" tendencies of expansion and shrinking as a significant example of contradiction in targeting the

\footnotetext{
${ }^{14}$ This is characteristic for a counter-urbanization phenomena (Kivell, P 2003, p.35)

15 This is not something new, for example the multiple nuclei model of Harris and Ullman.
}

future spatial development by the decidents. If the city of Braşov is an emigration place, the agglomeration area becomes an immigration one ${ }^{16}$.

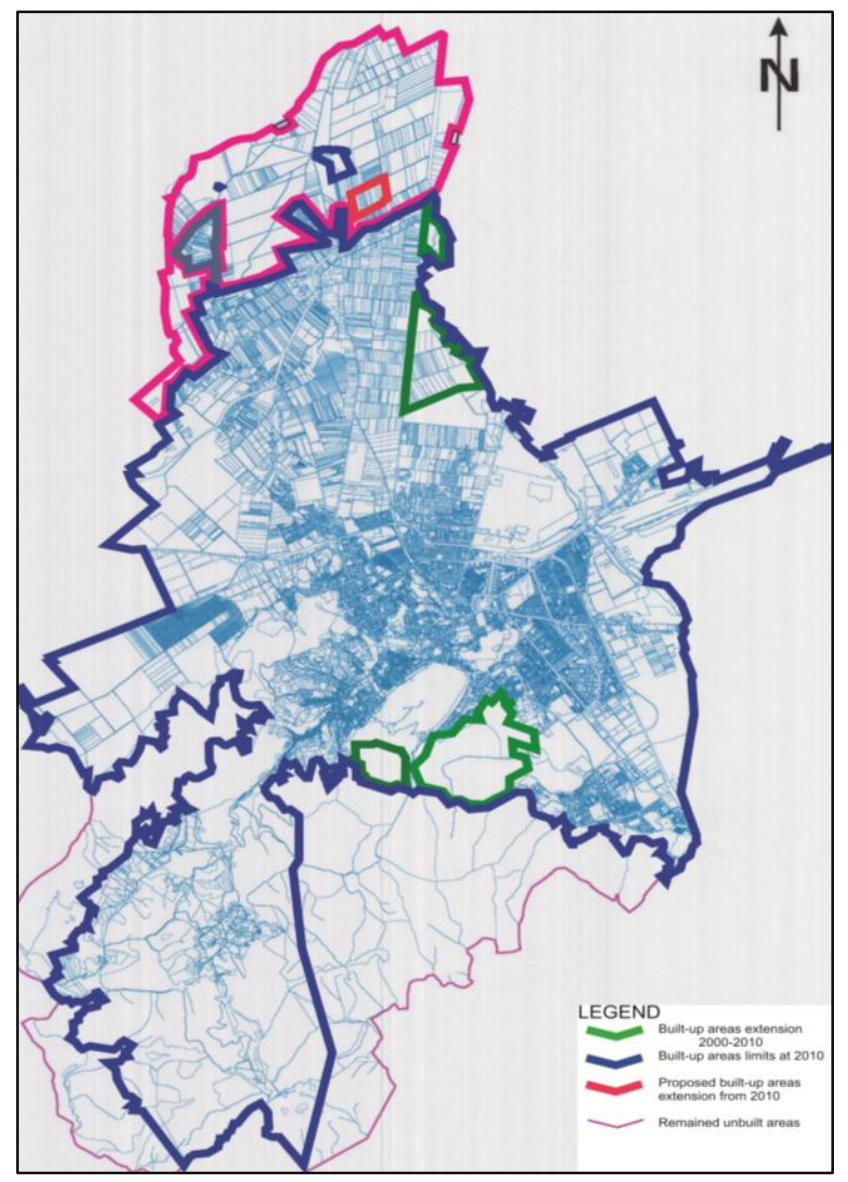

Figure 3. Proposed expansion of the built area of Brasov city. Author C. Sârbu

At a large scale the objective is to mitigate the possible unwanted phenomena generated by the urban growth, proposing a yellow-green belt in coordination with the development of a new urban small local scale pole of equilibrium (Prejmer), having a supplementary role to articulate with Sfântu Gheorghe city, and not for the last, offering the chance to preserve the urban specificity and scale of the human settlements of the agglomeration.

By the contrary, the urban growth of the built-up area of Brasov city, attempting to ensure by itself the spatial potential for future development, have as consequence the processes of agglutination and possible overlapping of the functional areas ${ }^{17}$.

\footnotetext{
${ }^{16}$ This means new permanent main or secondary residences for the inhabitants of Braşov city and secondary residence area for the people outside agglomeration area.

${ }_{17}$ "Urban sprawl is also caused by non-coordinated commercial zoning of land in peri-urban areas due to fragmented local government and planning systems, with each local municipality trying to maximize its local revenues" Tosics, I. (2011) quoted in EC, 2011, page 26
} 


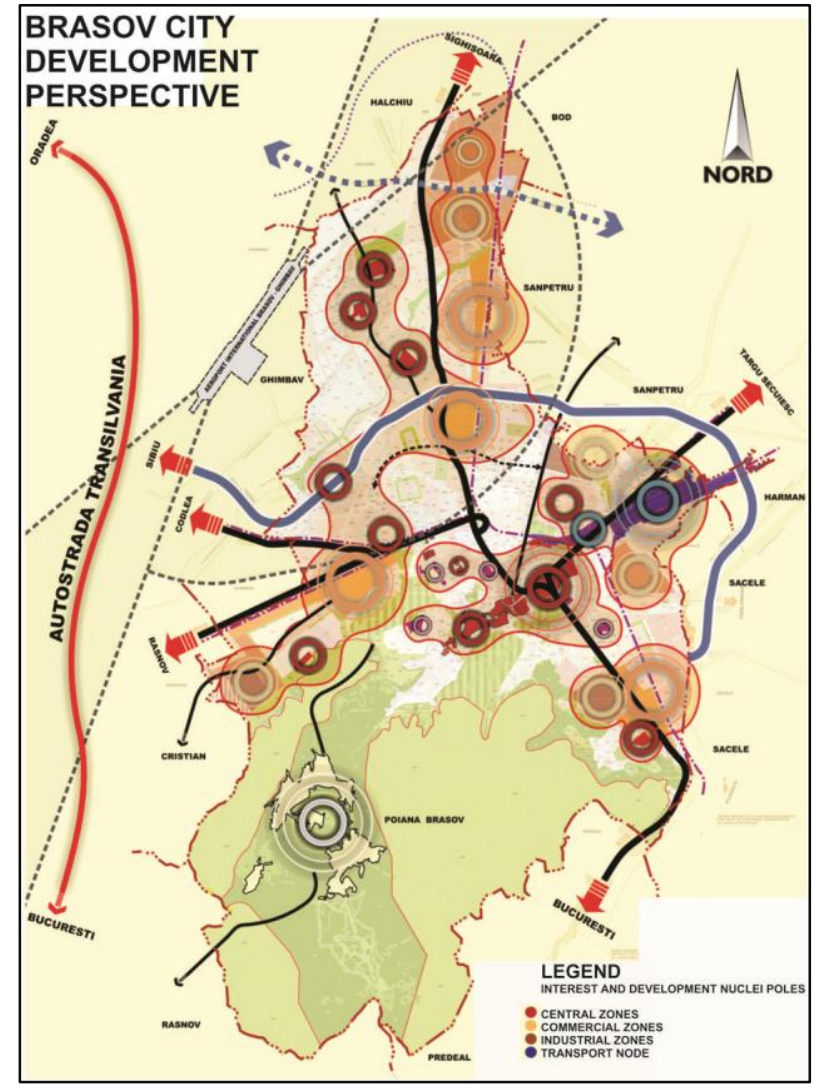

Figure 4. New proposed centres for the activities in the expansion zones area of Brasov city. Authors C. Sârbu, D. Plăcintescu

The change of administrative norms and laws in managing these kind of territory and the developing of the association of municipalities (as a prerequisite institutional structure for co-ordinated development process), appears as the imposed solution for a sustainable urban expansion, especially because Brasov agglomeration is one of the eight urban growth poles of Romania.

\section{Acknowledgements}

Many of the information and data of this work were mainly supported by the findings of the two planning projects Brasov Metropolitan Zone Study, 2007 and General Urban Plan of Brasov, 2011.

\section{References}

Basudeb, B 2010, Analysis of Urban Growth and Sprawl from Remote Sensing Data, Springer, Heidelberg, Dordrecht, London, New York.

Couch, C, Leontidou, L \& Petschel-Held, G (eds) 2007, Urban Sprawl in Europe - Landscapes, Land-Use Change E Policy, Blackwell Publishing Ltd.

ESPON 1.1.1. August 2004, Potentials for polycentric development in Europe, Nordregio.

European Commission - Directorate General for Regional Policy 2001, Cities of tomorrow - Challenges, visions, ways forward, Publications Office of the European Union, Luxembourg.

Hall, P \& Pain K 2006, The Polycentric Metropolis - Learning from Mega-City, Regions in Europe, Earthscan, Sterling VA Edition. London.

Ianos, I 2004, Dinamica urbană, Editura Tehnică, Bucureşti.

Kivell, $\mathrm{P}$ 2003, Land and the city - Patterns and processes of urban change, Routlege.

Maciocco, G (ed) 2008, The Territorial Future of the City, Volume 3, Series, Springer Science+Business Media B.V.

Sârbu, C 2006, Housing in Romania - A frame approach (original title: Locuirea în România: O abordare-cadru), Edition of Achitecture and Urban Planning University "Ion Mincu", Bucharest.

Sârbu, C (project director), 2007, Brasov Metropolitan Zone Study (Zona Metropolitana Brasov: PATJ și studiu urbanism), Beneficiary: Brasov County Council, University of Architecture and Urban Planning "Ion Mincu" Bucharest, Research Design, Expertise and Consulting Centre,

Sârbu, C (project director), 2011, General Urban Plan of Brasov city (Actualizare Plan Urbanistic General), Beneficiary: Brasov City Council, University of Architecture and Urban Planning "Ion Mincu" Bucharest, Research, Design, expertise and Consulting Centre. 